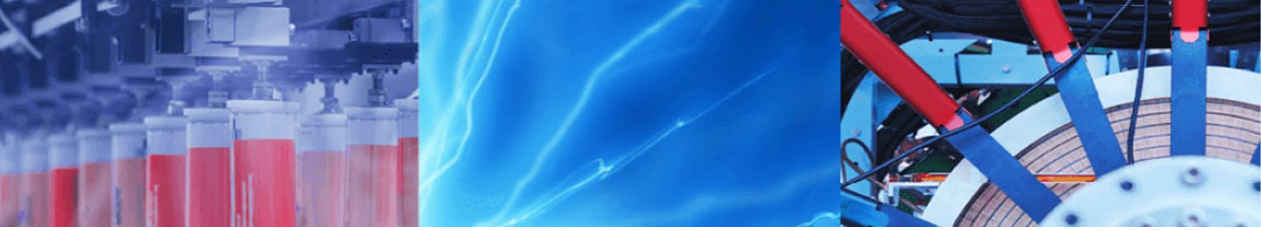

Research Article

\title{
Characterization and $\mathrm{NO}_{2}$ gas sensing performance of $\mathrm{CdO}: \ln _{2} \mathrm{O}_{3}$ polycrystalline thin films prepared by spray pyrolysis technique
}

\author{
Mahdi Hasan Suhail ${ }^{1} \cdot$ Hamad Saleh Al-Jumily² $\cdot$ Omed Gh. Abdullah ${ }^{3,4}(0$
}

(c) Springer Nature Switzerland AG 2018

\begin{abstract}
Polycrystalline $\mathrm{CdO}: \ln _{2} \mathrm{O}_{3}$ thin films for gas sensor applications were prepared on glass and silicon substrates by using one-step spray pyrolysis technique from the aqueous solution of $\mathrm{CdCl}_{2}$ and $\operatorname{lnCl} \mathrm{Cl}_{3}$ at a substrate temperature of $300{ }^{\circ} \mathrm{C}$. The structure, surface morphology, and the optoelectronic properties of prepared films were characterized respectively by means of X-ray diffraction (XRD), atomic force microscope and UV-visible spectroscopy. Based on the XRD results, the polycrystalline nature of CdO films has been confirmed, and $\mathrm{In}_{2} \mathrm{O}_{3}$ films were found to exhibit a preferred orientation along (222) diffracted plane. The grain size varies between 9.0 and $28.4 \mathrm{~nm}$. The results of Hall effect measurement of $\mathrm{CdO}: \ln _{2} \mathrm{O}_{3}$ thin films confirms that all films were an $n$-type semiconductor. The electrical properties of prepared thin films and their sensitivity to nitrogen dioxide $\left(\mathrm{NO}_{2}\right)$ gas are also studied. The influence of the operating temperature and $\mathrm{In}_{2} \mathrm{O}_{3}$ concentration on the $\mathrm{NO}_{2}$ response were investigated. It is found that all films are sensitive to $\mathrm{NO}_{2}$ gas, and the ideal operating temperature for the film contented $20 \mathrm{vol} \%$ of $\ln _{2} \mathrm{O}_{3}$ was found to be $200{ }^{\circ} \mathrm{C}$ at a gas concentration of $25 \mathrm{ppm}$. The sensing mechanism of the $\mathrm{CdO}: \mathrm{In}_{2} \mathrm{O}_{3}$ thin film is discussed and attributed to electron transfer between the sensing element and $\mathrm{NO}_{2}$ molecules.
\end{abstract}

Keywords Metal-oxide semiconductors · Structural · Morphology · Optoelectronic properties $\cdot \mathrm{NO}_{2}$ gas sensor $\cdot$ Sensitivity

\section{Introduction}

Over the last few decades, the transparent conducting oxide (TCO) semiconductor films have been extensively studied because they are the main component in hightechnological applications such as high performance organic light-emitting diodes, optoelectronic and solar cell devices $[1,2]$. The cadmium oxide $(\mathrm{CdO})$ film is one of the most promising TCOs semiconductor having high absorption and emission capacity of radiation in their narrow bandgap energy [3]. In addition, $\mathrm{CdO}$ exhibit fascinating features such as with narrow bandgap with high optical transparency in the visible region, and high electrical conductivity, which make it applicable in photoelectric devices, liquid crystal displays, semiconductor lasers, and gas sensors [4-6]. On the other hand, indium oxide $\left(\ln _{2} \mathrm{O}_{3}\right)$ thin films as another TCO semiconductors have distinctive and unique characteristics such as high optical transmittance, high electrical conductivity, good chemical stability, excellent adhesion to substrates and photochemical properties [7]. Therefore, $\ln _{2} \mathrm{O}_{3}$ has been used in a wide range of applications including photovoltaic devices, solar energy conversion, and flat panel displays [8,9]. Over the past few decades, numerous researchers have demonstrated that the metal-oxide-semiconductors can be widely used as sensors to detect various gases [10]. However, the

$\triangle$ Omed Gh. Abdullah, omed.abdullah@univsul.edu.iq | 'Department of Physics, College of Science, University of Baghdad, Baghdad, Iraq. ${ }^{2}$ Department of Physics, College of Education for Pure Sciences, University of Anbar, Anbar, Iraq. ${ }^{3}$ Department of Physics, College of Science, University of Sulaimani, Sulaymaniyah, Iraq. ${ }^{4}$ Komar Research Center, Komar University of Science and Technology,

Sulaymaniyah, Iraq. 
sensing properties of metal-oxide based sensors need to be further enhanced for excellent selectivity and fast response/recovery time to detect low concentration in a harsh environment. Many researchers have reported that the sensitivity and the selectivity of semiconducting metal-oxide based sensors could be improved by introducing suitable dopants or impurities into a semiconductor crystal [11-13]. It is well reported in the literature that the optical and electrical properties of TCO semiconductors depend strongly on the external doping level as well as sample preparation conditions [7]. Thus, in order to obtain an optimum characteristic of these type of materials, the dopant type, and its concentration as well as deposition conditions have to be carefully optimized.

A gas sensor device consists quite generally of an active material layer whose physical properties change in the presence of a determinate gas. The change can then be measured to detect the gas concentration [14]. The microscopic chemical interactions are selectively converted into a measurable electrical signal [15]. The improved selectivity and reversibility of the sensing process are the main requirements in the design and fabrication of sensors [16]. Gas sensors based on metal-oxides semiconductors are commonly used in the monitoring of toxic pollutants, not only because of their excellent thermal and physical stability but also due to their ability to provide the necessary sensitivity, selectivity, and stability required for measurements [12]. Despite the high sensitivity of several metaloxide materials, they often show high resistivity which significantly affects the performance and accuracy of the sensor. For example, nitrogen dioxide $\left(\mathrm{NO}_{2}\right)$, which is an oxidizing gas, might increase the resistance of the metaloxide films due to an increase in the $\mathrm{O}^{2-}$ ions in the $n$-type semiconductors [17].

To get a desire metal-oxide-semiconductors based sensors, with higher sensitivity, excellent selectivity, and more stability; many researchers have focused their researches on the analysis of sensing mechanism [11, 18]. Furthermore, many attempts have been made to improve the sensor performance by surface modification, metal-doping, and mixing various metal-oxides [19, 20]. It has previously been established that the mixing of metal-oxides, modifies the electron structures of the compound which result in changes to both the bulk and surface properties. Consequently, the resulting metal-oxides composite can achieve sensitivity and selectivity for gas detection far exceeds those achievable performance with the individual constituent of the composite. Studies of sensory phenomena in metal-oxide composites have shown that there are certain optimum compositions for which sensitivity reach maximum values [21-23]. On the other hand, the literature survey reveals that metal oxide gas-sensors composition is an essential factor that affected the surface morphology of the film [24]. Therefore, it is very important to investigate the morphological features of sensing materials which depend primarily on the nature of the components and the processing conditions. In the present investigation, spray pyrolysis technique has been used to prepare a polycrystalline $\mathrm{CdO}: \ln _{2} \mathrm{O}_{3}$ thin films with different concentration of $\ln _{2} \mathrm{O}_{3}$, to clarify the effect of the components on the structural, morphological, optical and electrical properties, to find the best conditions to enhance the gas-sensing performance towards nitrogen dioxide.

\section{Experimental part}

Polycrystalline $\mathrm{CdO}: \ln _{2} \mathrm{O}_{3}$ thin solid films were prepared using the spray pyrolysis technique. In this technique, an ionic solution containing the constituent elements of a compound is pulverized in the form of fine droplets. The droplets spray deposited on a preheated substrate and solidify. Based on the thermal decomposition of the precursor, a film of more stable compounds forms and adheres to the heated substrate. The solutions, used in the preparation of $\mathrm{CdO}: \ln _{2} \mathrm{O}_{3}$ thin films are the mixture of $1.1425 \mathrm{~g}$ of Cadmium chloride $\left(\mathrm{CdCl}_{2}\right)$, and $0.88212 \mathrm{~g}$ of Indium chloride $\left(\mathrm{InCl}_{3}\right)$ dissolved separately in $50 \mathrm{ml}$ of distilled water to obtain a molarity of $0.1 \mathrm{M}$ for each solution. The two solutions were mixed with the desired concentration of $\mathrm{InCl}_{3}$ (10, 20, 30 and $40 \mathrm{vol} \%$ ). The optimized deposition parameters such as nozzle-to-substrate distance $(29 \mathrm{~cm})$, spray time (5 s) and the spray interval $(50 \mathrm{~s})$ were kept constant during spraying. The substrate temperature was fixed at $300^{\circ} \mathrm{C}$. The temperature of the samples was controlled using a K-type thermocouple with an accuracy of $\pm 1{ }^{\circ} \mathrm{C}$. The film thickness was around $(d=400 \pm 10 \mathrm{~nm})$ was determined by an optical interferometeric method, using He-Ne laser with a wavelength of $\lambda=632 \mathrm{~nm}$, and by using the formula:

$d=\frac{\Delta x}{x} \frac{\lambda}{2}$

where $\Delta x$ is the distance between two fringes, and $x$ is fringe width.

The crystalline structure of the films under investigation was confirmed by X-ray diffraction (XRD, Shimadzu, DIFRACTOMETER/6000), with $\mathrm{CuK}_{a}$ radiation source $\lambda=1.5406 \AA$, in the $2 \theta$ range of $20^{\circ}$ to $60^{\circ}$.

The morphology of the films was detected by using atomic force microscope (AFM) model (AA3000 Scanning Probe Microscope SPM, tip NSC35/AIBS) from Angstrom Ad-Vance Inc.

The Hall-effect measurements were performed with a computer-controlled system. The values of carrier 
concentration $\left(n_{\mathrm{H}}\right)$ and Hall mobility $\left(\mu_{\mathrm{H}}\right)$ were calculated, respectively, using the following equations:

$n_{\mathrm{H}}=\frac{1}{R_{\mathrm{H}} e}$

$\mu_{\mathrm{H}}=\sigma\left|R_{\mathrm{H}}\right|$

where; $R_{\mathrm{H}}=\frac{V_{\mathrm{H}}}{l} \frac{d}{H}$

Here $R_{H}$ is Hall coefficient, $V_{H}$ is Hall voltage, $I$ is constant current, $\sigma$ is conductivity, $e$ is a charge of an electron, and $H$ is an applied magnetic field in Gauss.

In order to measure the $\mathrm{NO}_{2}$ gas sensing properties of the $\mathrm{CdO}: \ln _{2} \mathrm{O}_{3}$ thin solid films, the resistance of the sensor films was measured in air ambient and $\mathrm{NO}_{2}$ gas atmosphere, using digital multimeter Rigol DM3062 data acquisition system. For monitoring the response of the films to $\mathrm{NO}_{2}$ gas, the films were mounted in $250 \mathrm{~cm}^{3}$ homemade airtight container, and the $\mathrm{NO}_{2}$ gas of particular concentration was injected through a syringe. The resistance of the film was recorded before and after exposure to the $\mathrm{NO}_{2}$ gas. Gas sensitivity (s) is defined as the ration of the resistance in the air $\left(R_{\mathrm{a}}\right)$ to the resistance in the air containing $\mathrm{NO}_{2}$ gas $\left(R_{\mathrm{g}}\right)$, thus the sensitivity of the sensor can be determined from $S=R_{\mathrm{a}} / R_{\mathrm{g}}$. All the gas-sensing measurements were carried out at various operating temperatures, with $6 \mathrm{~V}$ bias voltages, and $\mathrm{NO}_{2}$ gas concentration was fixed at $25 \mathrm{ppm}$.

\section{Results and discussion}

\subsection{The XRD analysis}

Typical XRD pattern of the CdO: $\ln _{2} \mathrm{O}_{3}$ thin films prepared by pyrolysis method is presented in Fig. 1 . The pattern of CdO: $10 \% \mathrm{ln}_{2} \mathrm{O}_{3}$ show two diffraction peaks at $2 \theta$ values of $33.28^{\circ}$ and $38.54^{\circ}$ corresponded to pure $\mathrm{CdO}$, which are well-matched, respectively with the (111) and (200) planes of the cubic CdO phase according to JCPDS card No. $05-0640$ [25]. The low intensity of the observed diffraction peaks suggests a randomly distributed orientation of the crystallites. The existence of multiple diffraction peaks in the XRD pattern, confirms the polycrystalline nature of the CdO films [26]. The observed diffraction peaks appeared at $2 \theta$ values $21.18^{\circ}, 30.48^{\circ}, 32.40^{\circ}, 35.03^{\circ}, 37.32^{\circ}, 45.36^{\circ}$, and $50.74^{\circ}$ have been assigned, respectively, to the lattice planes (211), (222), (231), (400), (330), (341), and (440) of $\mathrm{In}_{2} \mathrm{O}_{3}$ according to JCPDS card No. 06-0416 [27]. It can be clearly seen that the intensity of all peak corresponding to $\ln _{2} \mathrm{O}_{3}$, increase with increasing indium mixture ratios in the prepared thin films. The high diffraction intensity of the peak around $2 \theta=30.48^{\circ}$ observed for all films indicates that the (222) direction is a preferred-orientated nature of the $\mathrm{In}_{2} \mathrm{O}_{3}$ films. The same behavior was also reported by Khan et al. [28] for nanostructured $\ln _{2} \mathrm{O}_{3}$ thin films deposited on glass substrates.

The mean grain size (G.S.) of the prepared samples was estimated from the full-width at the half-maximum (FWHM) of the highest intense peak at (222) plane, by using Debye-Scherrer formula [29, 30]. The calculated values of grain size are given in Table 1 . It can be seen that the grain size of $\mathrm{CdO}: \ln _{2} \mathrm{O}_{3}$ films increased by increasing $\ln _{2} \mathrm{O}_{3}$ concentration, due to aggregation effects at higher indium oxide concentrations.

\subsection{Morphological analysis}

In the extreme case of thin films, the surface roughness may be in the order of the film thickness and can affect all physical properties of the film such as optical, electrical, mechanical, magnetical, and gas sensor properties [23]. Figure 2 depicts the two- and three-dimensional atomic force microscopy (AFM) images for $\mathrm{CdO}: \ln _{2} \mathrm{O}_{3}$ thin films deposited on a glass substrate with a thickness of about $400 \mathrm{~nm}$. It can be seen clearly that all films exhibit a granular structure, distributed almost homogeneously on a crack-free surface. The finer morphology and roughness of the films can be seen. The average grain size and surface roughness analysis of the grown $\mathrm{CdO}: \ln _{2} \mathrm{O}_{3}$ thin films varied significantly with $\ln _{2} \mathrm{O}_{3}$ concentration, as tabulated in Table 2. The surface roughness of the films can be attributed to the grain growth of different sizes [31]. It is well reported in the literature that, the high specific surface area of sensing material (maximum roughness) usually has positive effects on the gas-sensing performance [17]. Thus the sample with $20 \%$ of $\operatorname{In}_{2} \mathrm{O}_{3}$ expected to have improved sensitivity due to its higher roughness.

\subsection{Transmission spectra analysis}

The effect of $\ln _{2} \mathrm{O}_{3}$ concentration on the optical properties of $\mathrm{CdO}$ films was identified from the optical transmittance spectrum, which is the most direct and simplest technique to investigate the band structure of semiconductor materials $[32,33]$. Figure 3 shows the optical transmittance spectra of $C d O: \ln _{2} \mathrm{O}_{3}$ thin films with different vol\% of $\ln _{2} \mathrm{O}_{3}$ and in the wavelength ranging from 300 to $1100 \mathrm{~nm}$. The transmittance spectra of all samples under investigation exhibit high transmittance values in the visible and nearinfrared wavelengths in the order of $90 \%$. Such films would have potential applications in optoelectronic devices. The decreased in transmittance with increasing of $\ln _{2} \mathrm{O}_{3}$ mixing ratio, can be referred to the increase in the absorbance within visible and near-infrared regions of the spectrum. 
Fig. 1 The XRD pattern of the prepared $\mathrm{CdO}: \ln _{2} \mathrm{O}_{3}$ thin films

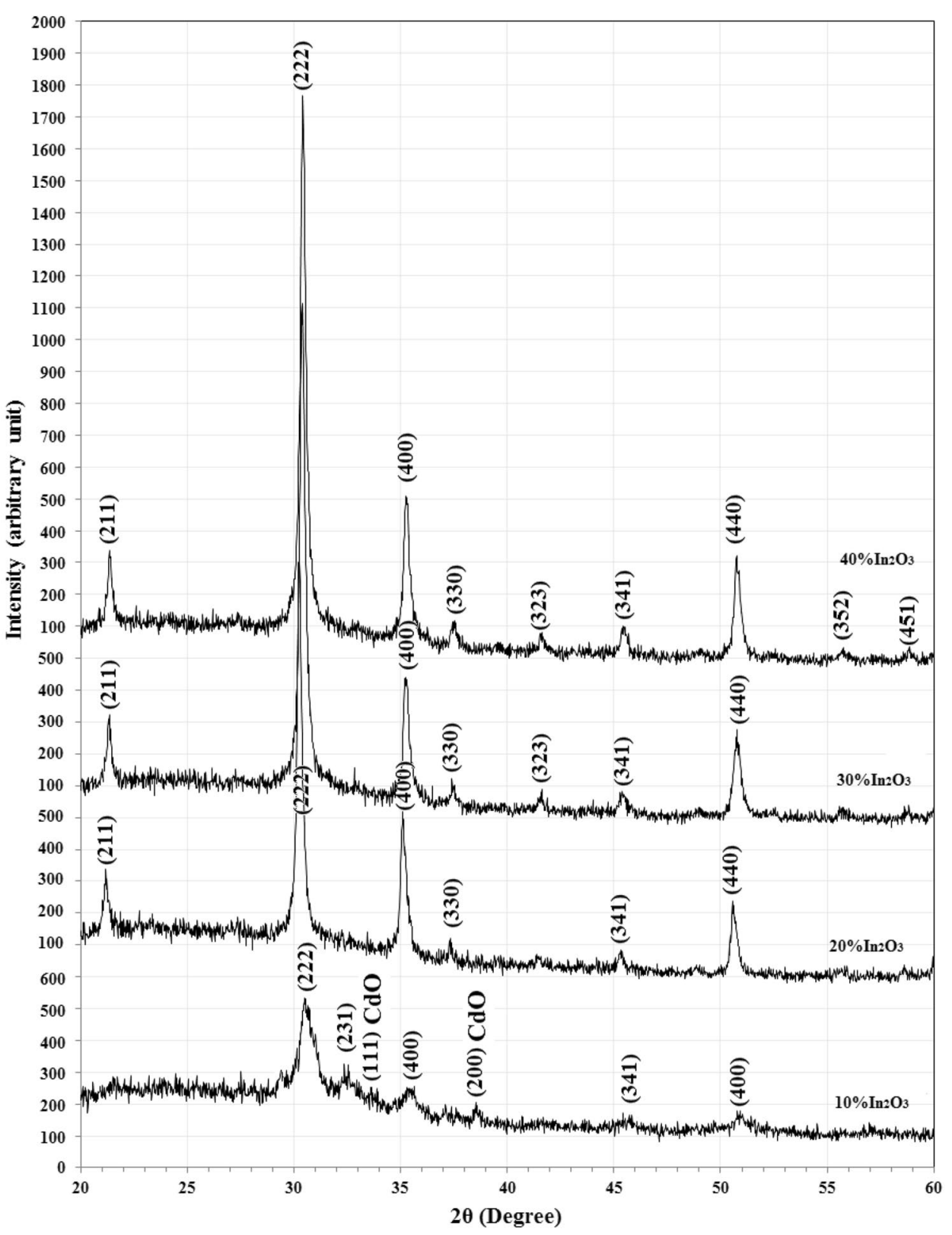

Table 1 XRD parameters for $\mathrm{CdO}: \ln _{2} \mathrm{O}_{3}$ thin films, at highest intense peak at (222)

\begin{tabular}{llllcl}
\hline $\begin{array}{l}\mathrm{In}_{2} \mathrm{O}_{3} \\
\text { content }\end{array}$ & $2 \theta\left(^{\circ}\right)$ & FWHM $\left(^{\circ}\right)$ & $\begin{array}{l}d_{h k l} \text { Exp. } \\
(\AA)\end{array}$ & G.S. $(\mathrm{nm})$ & $d_{h k l}$ Std. $(\AA)$ \\
\hline $10 \%$ & 30.4831 & 0.9179 & 2.9301 & 9.0 & 2.9214 \\
$20 \%$ & 30.2899 & 0.3382 & 2.9484 & 24.3 & 2.9214 \\
$30 \%$ & 30.3865 & 0.3865 & 2.9392 & 21.3 & 2.9214 \\
$40 \%$ & 30.4348 & 0.2898 & 2.9347 & 28.4 & 2.9214 \\
\hline
\end{tabular}

Moreover, in the transparent metal-oxides films, the metalto-oxygen ratio in the film decides the percentage of the optical transmittance. Generally, a metal-rich thin film shows less transparency [34-36]. Hence the decrease in optical transmittance for higher $\ln _{2} \mathrm{O}_{3}$ concentration samples might also be attributed to the increase in metal to oxygen ratio, $(\mathrm{Cd}+\mathrm{In}) / \mathrm{O}$. The transmittance spectrum of CdO: $\ln _{2} \mathrm{O}_{3}$ thin films is characterized by a sharp increase in the wavelength range $310-380 \mathrm{~nm}$, which is an identification of good crystallinity nature of these films [37]. This is in agreement with the results of the XRD patterns shown in Fig. 1.

\subsection{The optical band gap calculation}

The optical band-gap energy of $\mathrm{CdO}: \ln _{2} \mathrm{O}_{3}$ thin films with various $\ln _{2} \mathrm{O}_{3}$ contents were calculated by plot the 
Fig. 2 AFM images of CdO: $\ln _{2} \mathrm{O}_{3}$ thin films with various $\ln _{2} \mathrm{O}_{3}$ concentration
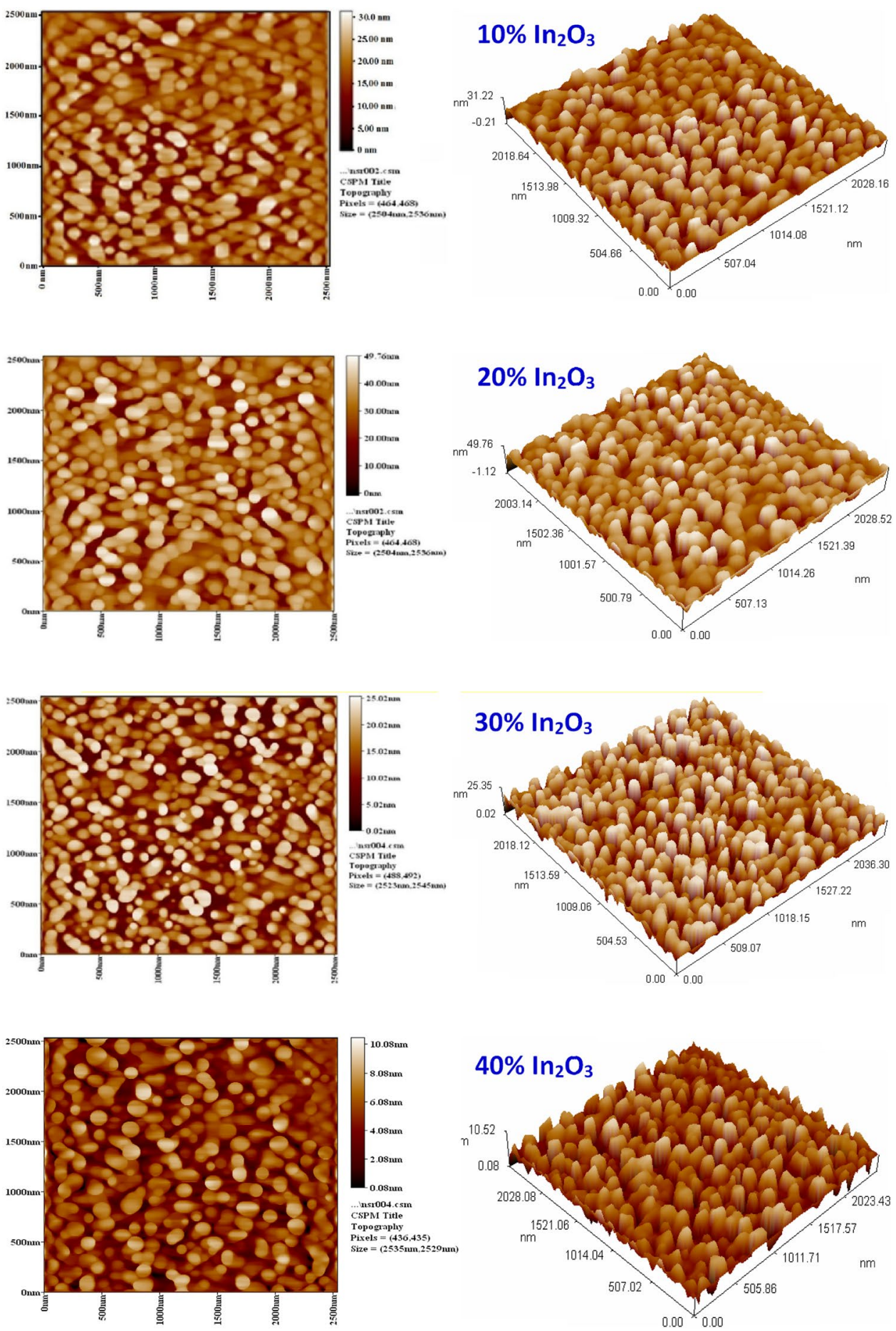

variation of $(a h u)^{2}$ with photon energy (hu), as shown in Fig. 4. The straight line in Fig. 4 is an indicator of the presence of direct allowed optical transition. According to Tauc's relation, the intercepts of the best fit line of the plot on hu-axis give the value of direct allowed optical band-gap [38, 39]. The extracted optical band-gap for CdO: $\ln _{2} \mathrm{O}_{3}$ thin films were found to be $3.60,3.42,3.40$, and $3.30 \mathrm{eV}$, for $10,20,30$, and 40 vol\% mixed ratio of
$\mathrm{In}_{2} \mathrm{O}_{3}$, respectively. There was shifting towards lower energies with increasing $\ln _{2} \mathrm{O}_{3}$ concentration. The addition of $\ln _{2} \mathrm{O}_{3}$ may have led to the formation of localized levels within the forbidden band gap, which contributes to increasing the number of electrons that reach the conduction band-gap [40]. The wide direct band-gap of the samples under investigation makes these films good 
Table 2 Average grain size, average roughness and average r.m.s roughness values of $\mathrm{CdO}: \ln _{2} \mathrm{O}_{3}$ thin films

\begin{tabular}{lcll}
\hline $\mathrm{In}_{2} \mathrm{O}_{3}$ content & $\begin{array}{l}\text { Average grain } \\
\text { size }(\mathrm{nm})\end{array}$ & $\begin{array}{l}\text { Average rough- } \\
\text { ness }(\mathrm{nm})\end{array}$ & $\begin{array}{l}\text { r.m.s } \\
\text { roughness } \\
(\mathrm{nm})\end{array}$ \\
\hline $10 \%$ & 79.76 & 4.07 & 4.91 \\
$20 \%$ & 103.97 & 6.24 & 7.79 \\
$30 \%$ & 71.87 & 4.63 & 5.4 \\
$40 \%$ & 86.56 & 1.48 & 1.8 \\
\hline
\end{tabular}

material for potential applications in optoelectronic devices such as solar cell, and photodetectors.

\subsection{Hall effect measurements}

The Hall effect measurement is a useful tool to provide the basic electrical parameters to find the suitability of metaloxide-semiconductor for particular applications [41]. The Hall measurements were performed at room temperature for $\mathrm{CdO}: \mathrm{In}_{2} \mathrm{O}_{3}$ thin films deposited on a glass substrate at a temperature of $300^{\circ} \mathrm{C}$ with different $\ln _{2} \mathrm{O}_{3}$ contents. The conductivity $(\sigma)$, Hall coefficient $\left(R_{\mathrm{H}}\right)$, carrier concentration $\left(n_{H}\right)$, and carrier mobility $\left(\mu_{H}\right)$ were calculated for each film, and the values are arranged in Table 3. The negative sign of Hall coefficients for all $\mathrm{CdO}: \mathrm{In}_{2} \mathrm{O}_{3}$ thin films confirmed the $n$-type nature conductivity of this system. This is caused due to the existence of defects such as oxygen vacancies and/or intrinsic interstitial cadmium atoms, which can be easily ionized $[42,43]$. The induced electrons from this process contribute to the conduction of electricity, causing $\mathrm{CdO}$ to act as an n-type semiconductor.

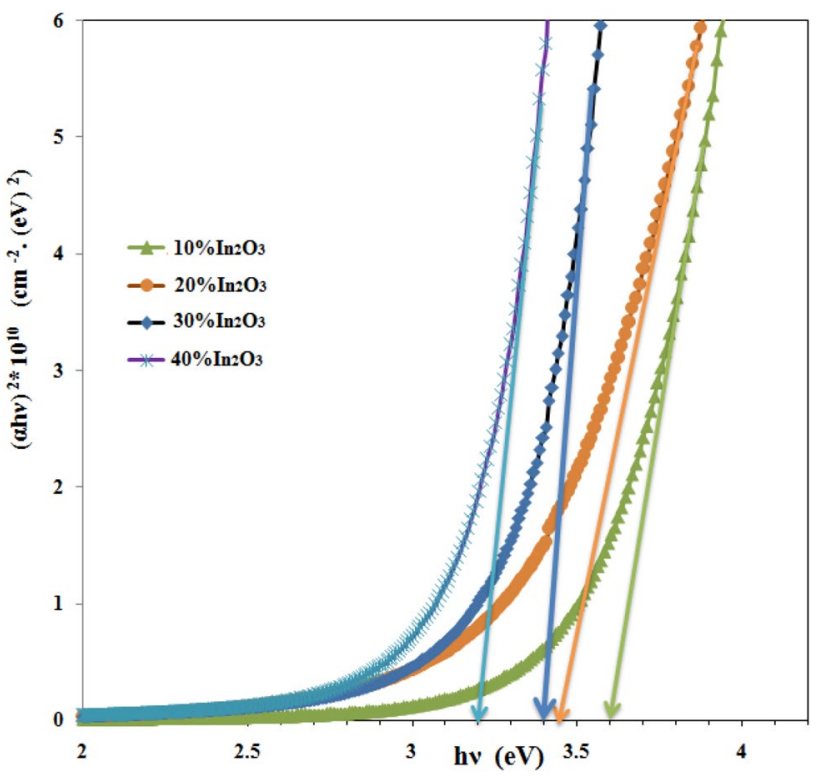

Fig. 4 Dependence of $(a h v)^{2}$ on photon energies $(h v)$ for $\mathrm{CdO}: \ln _{2} \mathrm{O}_{3}$ thin films at various $\ln _{2} \mathrm{O}_{3}$ concentrations

\subsection{Gas-sensing performance}

Sensing tests aimed to find the optimal conditions of operation of sensors for $\mathrm{NO}_{2}$ gas. It is well accepted that doping can improve the gas-sensing performance of the metal-oxide semiconductor-based sensors for selected gas [44]. Figures 5, 6, 7 and 8 show the resistance-time variation of $\mathrm{CdO}: \ln _{2} \mathrm{O}_{3}$ thin film sensors with different $\ln _{2} \mathrm{O}_{3}$ concentrations, at various testing temperatures. The $\mathrm{NO}_{2}$ gas concentration was fixed at $25 \mathrm{ppm}$. The moment at
Fig. 3 A transmission as a function of the wavelength for $\mathrm{CdO}: \ln _{2} \mathrm{O}_{3}$ thin films

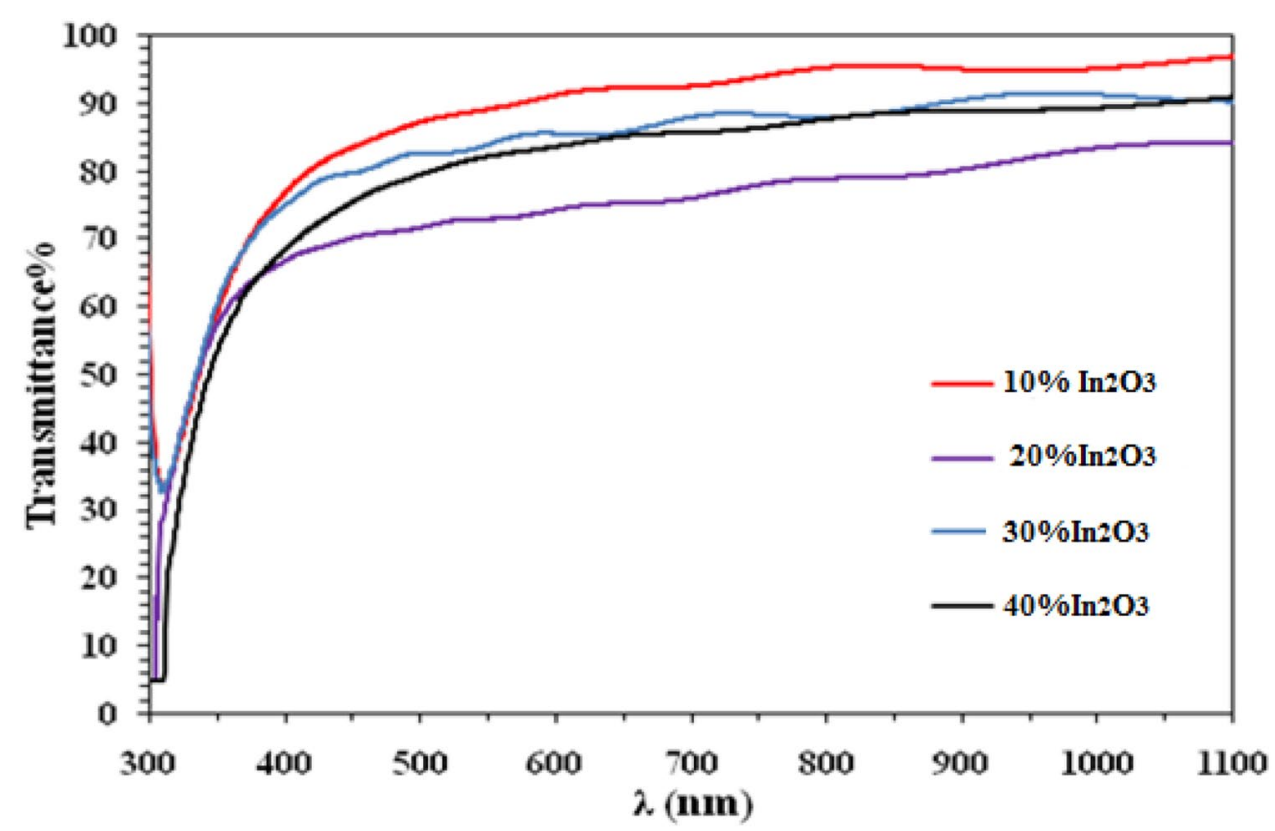


Table 3 Hall measurements of CdO: $\ln _{2} \mathrm{O}_{3}$ thin films at different $\ln _{2} \mathrm{O}_{3}$ concentration

\begin{tabular}{lcccc}
\hline $\mathrm{In}_{2} \mathrm{O}_{3}$ content & $n_{\mathrm{H}}\left(\mathrm{cm}^{-3}\right) \times 10^{17}$ & $R_{\mathrm{H}}\left(\mathrm{cm}^{3} / \mathrm{C}\right)$ & $\sigma_{\mathrm{RT}}\left(\Omega^{-1} \cdot \mathrm{cm}^{-1}\right)$ & $\mu_{\mathrm{H}}\left(\mathrm{cm}^{2} / \mathrm{V} \mathrm{s}\right)$ \\
\hline $10 \%$ & 38.50 & -1.620 & 0.9028 & 1.462 \\
$20 \%$ & 4.360 & -14.30 & 0.7444 & 10.64 \\
$30 \%$ & 2.409 & -25.91 & 0.7172 & 18.58 \\
$40 \%$ & 1.826 & -34.18 & 1.0120 & 13.32 \\
\hline
\end{tabular}
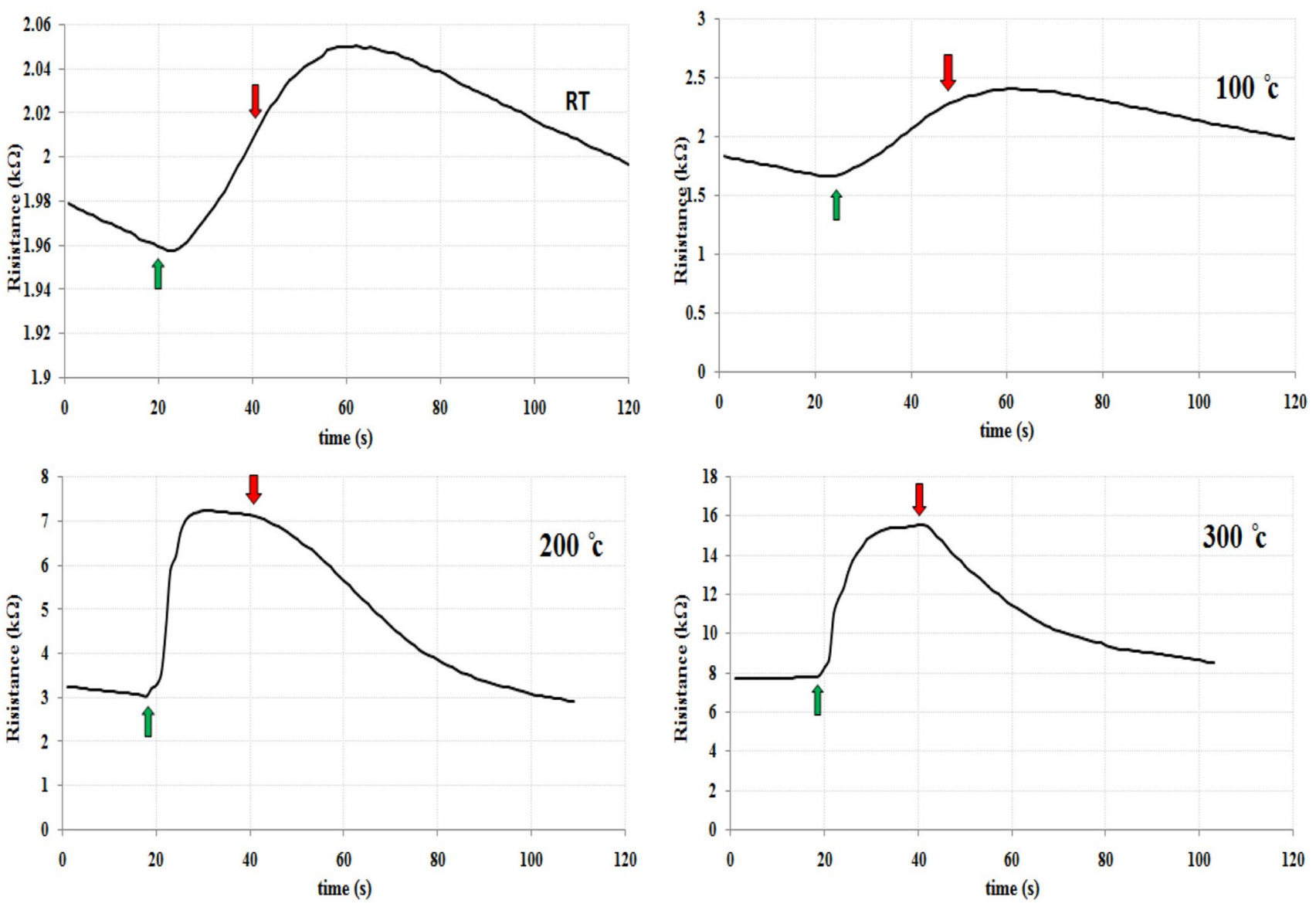

Fig. 5 The variation of resistance with time for $\mathrm{CdO}$ mixed $10 \% \ln _{2} \mathrm{O}_{3}$

which the gas turn-on and turn-off are monitored on the figures. It can be seen from these figures that the values of electrical resistance for all samples continuously increases with increasing operating temperature. Also, it is evident that the sensor resistance increased when the films were exposed to the $\mathrm{NO}_{2}$ gas for all temperatures, and a maximum sensor response was achieved at about $200^{\circ} \mathrm{C}$. This is in consistency with the result reported by Ferro et al. [45] for sprayed CdO:ZnO thin film-based $\mathrm{NO}_{2}$ gas sensors. They noted that the maximum conductance was achieved in the temperature range $200-230^{\circ} \mathrm{C}$, they attribute this behavior to the increase of the valence electrons concentration produced by thermal excitation.
Two different models mainly describe the sensing mechanism of metal-oxide semiconductor based sensors: the ionosorption model and the oxygen-vacancy model. The ionosorption model considers the changes in the electric surface potential that result from the gas adsorption, ionization and redox reactions. The oxygen-vacancy model focus on the reaction between gas molecules and oxygen vacancies $[11,46]$. In the present study, the $\mathrm{NO}_{2}$ gas molecules are adsorbed on the surface of the $\mathrm{CdO}: \mathrm{In}_{2} \mathrm{O}_{3}$ film due to oxidizing nature of $\mathrm{NO}_{2}$ molecules, resulting the electrons transfer occurrence from sensing element to the adsorbed $\mathrm{NO}_{2}$ gas on the surface of the film and forming $\left(\mathrm{NO}_{2}\right)^{-}$. The process leads to the reduction in electron 

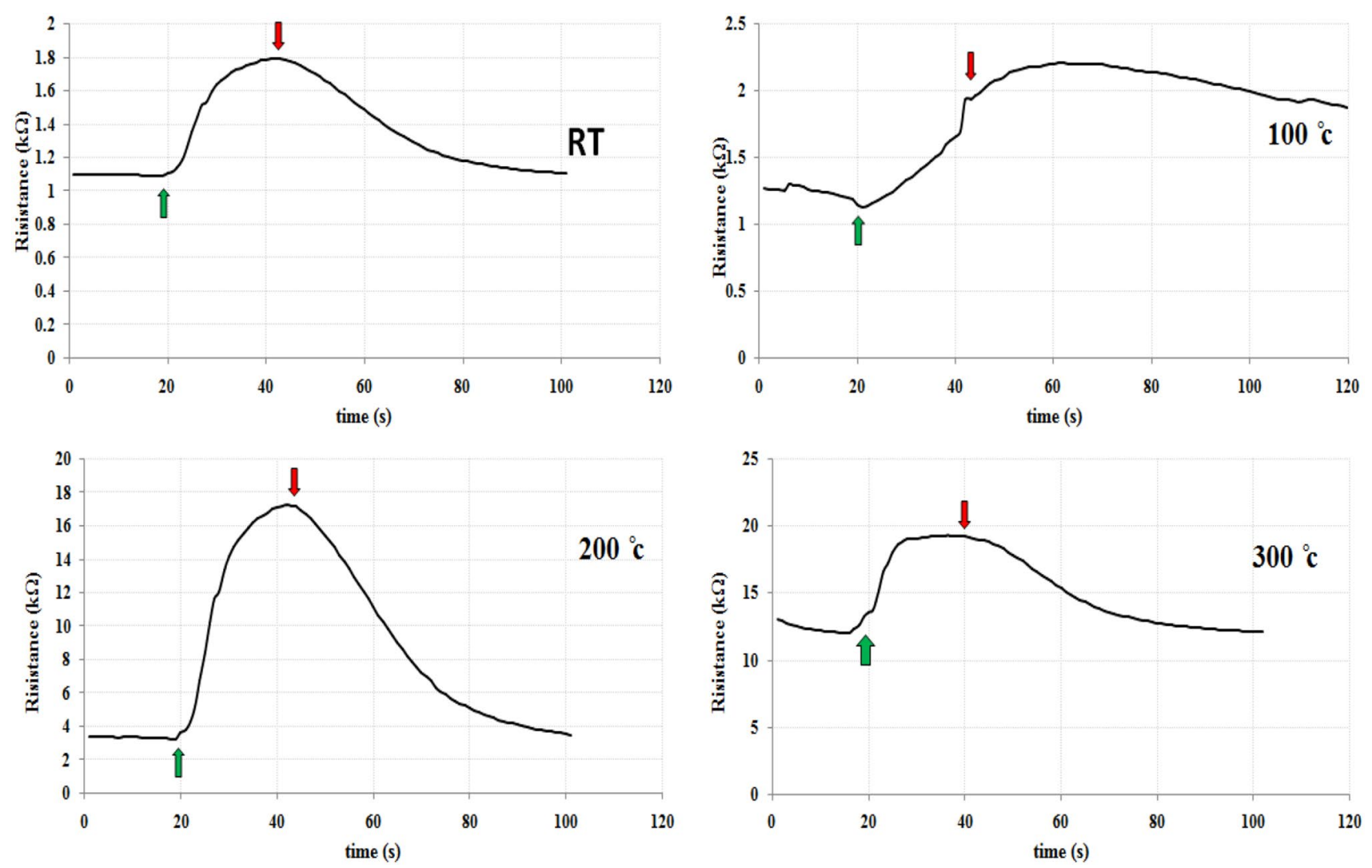

Fig. 6 The variation of resistance with time for $\mathrm{CdO}$ mixed $20 \% \ln _{2} \mathrm{O}_{3}$

density of the materials, and hence an increase in the value of resistance upon exposure to $\mathrm{NO}_{2}$ gas $[20,47]$.

It can be seen in Figs. 5, 6, 7 and 8, that the films responsivity increases as the temperature increases from room temperature to a $200^{\circ} \mathrm{C}$ and this shows a typical negative temperature coefficient of resistance (NTCR). When the temperature exceeds $200^{\circ} \mathrm{C}$, the sensor film sensitivity is slowly decreased which led to the positive temperature coefficient of resistance (PTCR). This behavior reveals that the interaction between $\mathrm{NO}_{2}$ gas molecules and the metal-oxide surface is thermally activated. The sensing properties of the film can be determined by considering the processes of adsorption, reaction, and desorption of gas molecules on the sensing surface [48]. The optimum operating temperature depends on the sensing materials and the kind of gases to detect, this could result from the change of the adsorption and desorption rates of gas molecules on the surface of the sensing element [12]. Thus, the maximum sensor response at $200^{\circ} \mathrm{C}$ is due to an increase in the reaction rate of $\mathrm{NO}_{2}$ molecules on the sensing surface, which might be attributed mainly to enhance in the adsorption rather than desorption rate. The variation of the sensitivity with the operating temperature for $\mathrm{CdO}$ mixed with different concentrations of $\ln _{2} \mathrm{O}_{3}$ is shown in Fig. 9. It is obvious that $\mathrm{CdO}$ thin films mixed with $20 \%$ $\ln _{2} \mathrm{O}_{3}$ exhibit maximum sensitivity towards $\mathrm{NO}_{2}$ gas at a temperature of $200^{\circ} \mathrm{C}$. For most metal-oxide gas sensors, the high operating temperature is due to the reaction temperature of $\mathrm{O}^{-}$[12]. According to Pozos et al. [49], the sensitivity of the metal oxide based sensors will increase as the effective surface area increased, which directly related to the roughness of the film which caused a bigger contact area for detecting gas. Thus the maximum sensitivity of CdO-20\% $\ln _{2} \mathrm{O}_{3}$ film can be attributed to the increase in both particle size and surface roughness as confirmed by $\mathrm{XRD}$ and AFM measurements. 

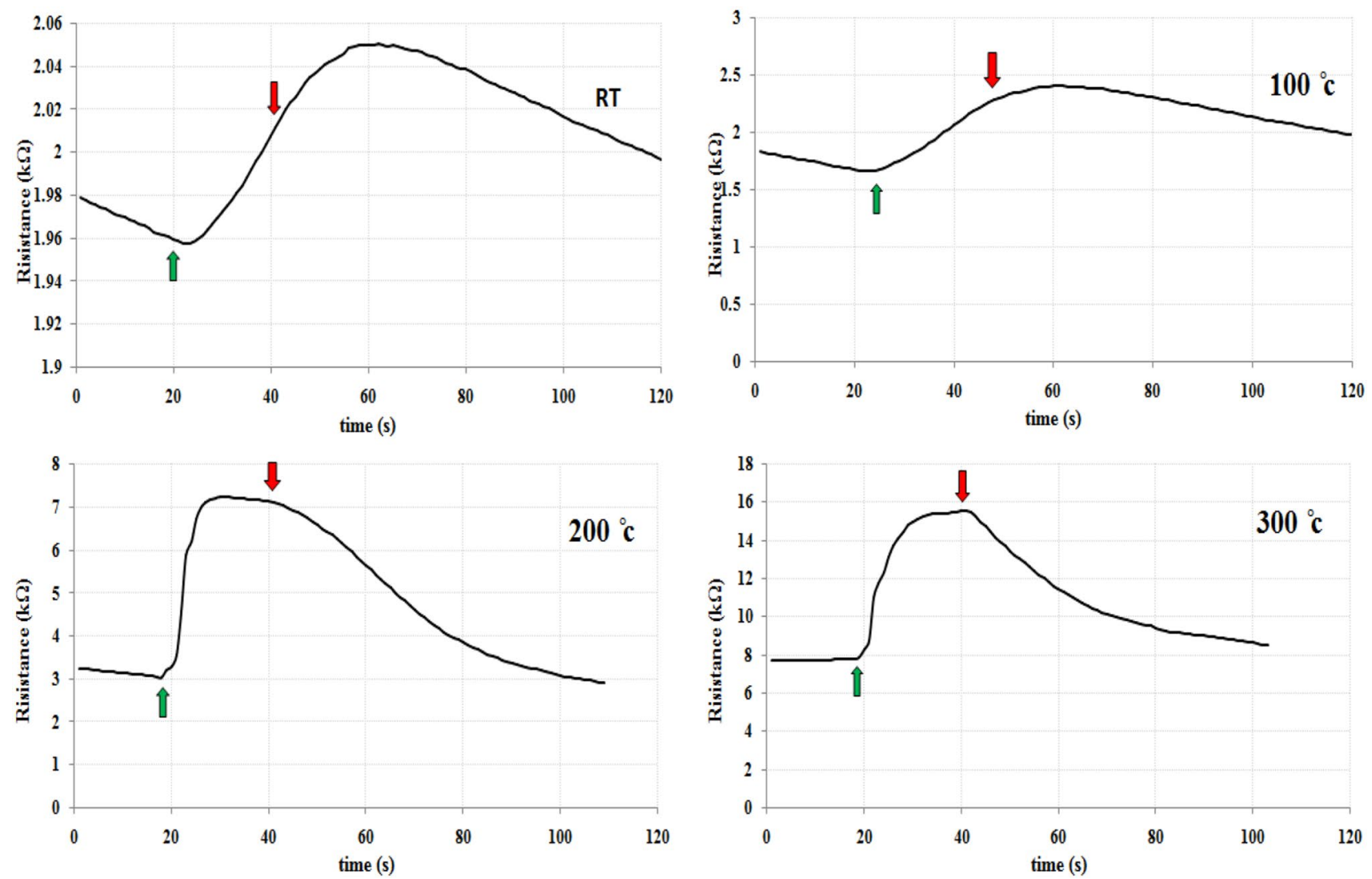

Fig. 7 The variation of resistance with time for $\mathrm{CdO}$ mixed $30 \% \ln _{2} \mathrm{O}_{3}$

\section{Conclusions}

Metal-oxide $\mathrm{NO}_{2}$ gas sensor based on $\mathrm{CdO}: \operatorname{In}_{2} \mathrm{O}_{3}$ thin films deposited by spray pyrolysis techniques has been extensively studied. The XRD analysis revealed that the films are polycrystalline in nature with a preferred-orientation along the (222) diffracted plane. The surface morphology and

the optical band gap of $\mathrm{CdO}: \ln _{2} \mathrm{O}_{3}$ thin films were affected by the $\ln _{2} \mathrm{O}_{3}$ concentration. The Hall effect measurements confirm the n-type nature of $\mathrm{CdO}: \ln _{2} \mathrm{O}_{3}$ thin films. The structure of $\mathrm{CdO}: \ln _{2} \mathrm{O}_{3}$ exhibits high sensitivity with rapid response/recovery which is one of the main features of this sensor. The maximum sensitivity for the film contented 

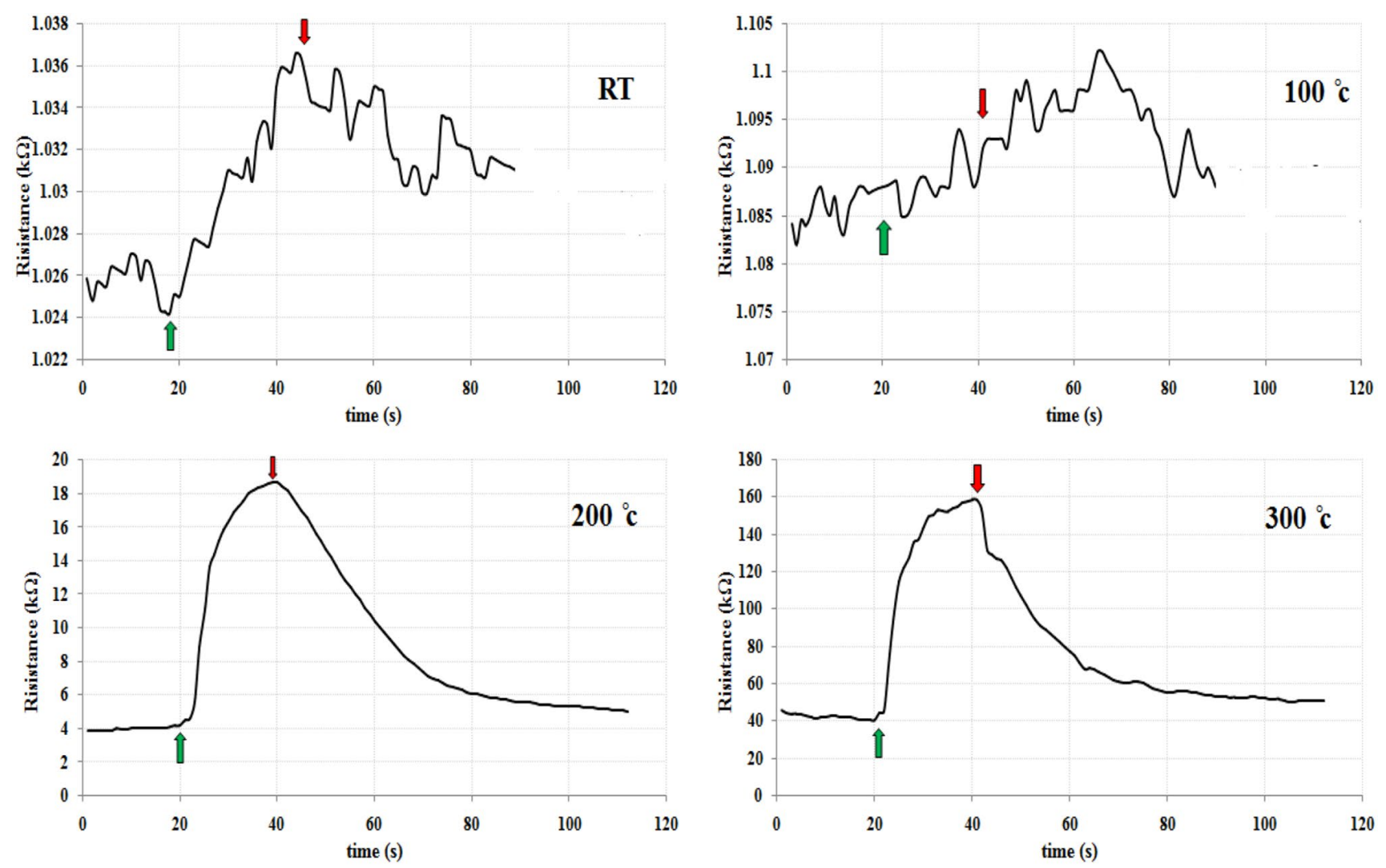

Fig. 8 The variation of resistance with time for $\mathrm{CdO}$ mixed $40 \% \mathrm{In}_{2} \mathrm{O}_{3}$

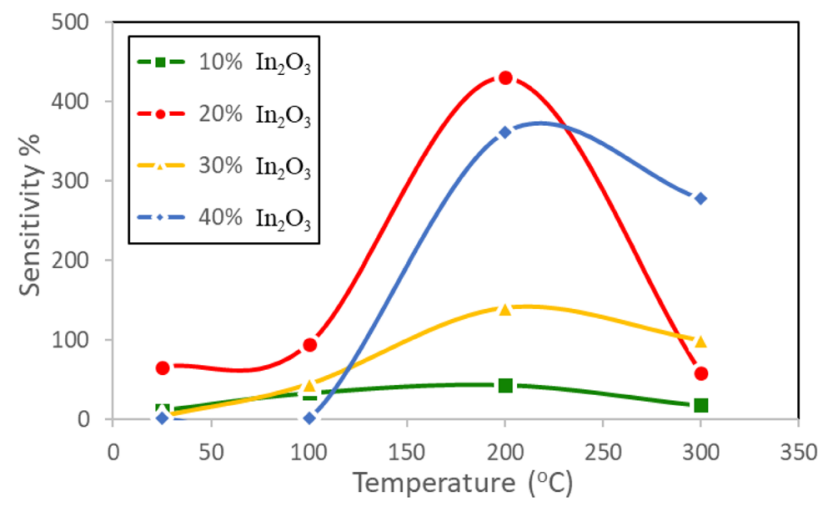

\section{References}

1. Ohta H, Hosono H (2004) Transparent oxide optoelectronics. Mater Today 7:42-51

2. Gurumurugan K, Mangalaraj D, Narayandass SK (1995) Structural characterization of cadmium oxide thin films deposited by spray pyrolysis. J Cryst Growth 147:355-360

3. Lokhande BJ, Patil PS, Uplane MD (2004) Studies on cadmium oxide sprayed thin films deposited through non-aqueous medium. Mater Chem Phys 84:38-242

4. Aydin R, Sahin B (2017) Comprehensive research on physical properties of $\mathrm{Zn}$ and $\mathrm{M}(\mathrm{M}: \mathrm{Li}, \mathrm{Na}, \mathrm{K})$ double doped cadmium oxide (CdO) nanostructures using SILAR method. Ceram Int 43:9285-9290

5. Sahin B, Bayansal F, Yuksel M, Biyikli N, Cetinkara HA (2014) Effect of coumarin concentration on the physical properties of $\mathrm{CdO}$ nanostructures. Ceram Int 40:5237-5243

Fig. 9 The sensitivity as a function of operating temperature for $\mathrm{CdO}$ mixed with different concentrations of $\ln _{2} \mathrm{O}_{3}$

20 vol\% of $\ln _{2} \mathrm{O}_{3}$ towards $\mathrm{NO}_{2}$ gas has been obtained at $200^{\circ} \mathrm{C}$.

Acknowledgements The authors would like to express their sincere gratitude to the Department of Physics, College of Science, at Baghdad University for the facility in their laboratories.

\section{Compliance with ethical standards}

Conflict of interest The authors declare that they have no conflict of interest.

6. Lu Q, Wang SF, Li LJ, Wang JL, Dai SY, Yu W, Fu GS (2014) Electrical and thermal transport properties of $\mathrm{CdO}$ ceramics. Sci China Phys Mech Astron 57:1644-1648

7. Habibi MH, Talebian N (2005) The effect of annealing on structural, optical and electrical properties of nanostructured tin doped indium oxide thin films. Acta Chim Slov 52:53-59

8. Henriquez R, Munoz E, Dalchiele EA, Marotti RE, Martin F, Leinen D, Ramos-Barrado JR, Gomez H (2013) Electrodeposition of $\operatorname{In}_{2} \mathrm{O}_{3}$ thin films from a dimethylsulfoxide based electrolytic solution. Phys Status Solidi A 210:297-305

9. Suhail MH, Abdullah OG, Ahmed RA, Aziz SB (2018) Photovoltaic properties of doped zinc sulfide/n-Si heterojunction thin films. Int J Electrochem Sci 13:1472-1483 
10. Fine GF, Cavanagh LM, Afonja A, Binions R (2010) Metal oxide semi-conductor gas sensors in environmental monitoring. Sensors 10:5469-5502

11. Zhang J, Qin Z, Zeng D, Xie C (2017) Metal-oxide-semiconductor based gas sensors: screening, preparation, and integration. Phys Chem Chem Phys 19:6313-6329

12. Liu X, Cheng S, Liu H, Hu S, Zhang D, Ning H (2012) A survey on gas sensing technology. Sensors 12:9635-9665

13. Lee SP (2017) Electrodes for semiconductor gas sensors. Sensors $17: 683$

14. Bai H, Shi G (2007) Gas sensors based on conducting polymers. Sensors 7:267-307

15. Suhail MH, Ramadan AA, Aziz SB, Abdullah OG (2017) Chemical surface treatment with toluene to enhances sensitivity of $\mathrm{NO}_{2}$ gas sensor based on CuPcTs/Alq 3 thin films. J Sci Adv Mater Devices 2:301-308

16. Kruis FE, Fissan H, Peled A (1998) Synthesis of nanoparticles in the gas phase for electronic, optical and magnetic applications-review. J Aerosol Sci 29:511-535

17. Ferro R, Rodriguez JA, Bertrand P (2005) Development and characterization of a sprayed $\mathrm{ZnO}$ thin film-based $\mathrm{NO}_{2}$ sensor. Phys Status Solidi C 2:3754-3757

18. Yang L, Xie C, Zhang G, Zhao J, Yu X, Zeng D, Zhang S (2014) Enhanced response to $\mathrm{NO}_{2}$ with $\mathrm{CuO} / \mathrm{ZnO}$ laminated heterostructured configuration. Sens Actuators, B 195:500-508

19. Bai S, Li D, Han D, Luo R, Chen A, Chung CL (2010) Preparation, characterization of $\mathrm{WO}_{3}-\mathrm{SnO}_{2}$ nanocomposites and their sensing properties for $\mathrm{NO}_{2}$. Sens Actuators, $\mathrm{B}$ 150:749-755

20. Li TT, Bao N, Geng AF, Yu H, Yang Y, Dong XT (2018) Study on room temperature gas-sensing performance of $\mathrm{CuO}$ film-decorated ordered porous $\mathrm{ZnO}$ composite by $\ln _{2} \mathrm{O}_{3}$ sensitization. R Soc Open Sci 5:171788

21. Trakhtenberg LI, Gerasimov GN, Gromov VF, Belysheva TV, llegbusi OJ (2012) Effect of composition on sensing properties of $\mathrm{SnO}_{2}+\mathrm{In}_{2} \mathrm{O}_{3}$ mixed nanostructured films. Sens Actuators, B 169:32-38

22. Neri G, Bonavita A, Micali G, Rizzo G, Pinna N, Niederberger M, $\mathrm{Ba} J$ (2008) Effect of the chemical composition on the sensing properties of $\mathrm{In}_{2} \mathrm{O}_{3}-\mathrm{SnO}_{2}$ nanoparticles synthesized by a nonaqueous method. Sens Actuators, B 130:222-230

23. Kim KW, Cho PS, Kim SJ, Lee JH, Kang CY, Kim JS, Yoon SJ (2007) The selective detection of $\mathrm{C}_{2} \mathrm{H}_{5} \mathrm{OH}$ using $\mathrm{SnO}_{2}-\mathrm{ZnO}$ thin film gas sensors prepared by combinatorial solution deposition. Sens Actuators, B 123:318-324

24. Abdulameer AF, Suhail MH, Abdullah OG, Al-Essa IM (2007) Fabrication and characterization of NiPcTs organic semiconductors based surface type capacitive-resistive humidity sensors. J Mater Sci: Mater Electron 28:13472-13477

25. Zargar RA, Chackrabarti S, Arora M, Hafiz AK (2016) Synthesis, characterization and interpretation of screen-printed nanocrystalline $\mathrm{CdO}$ thick film for optoelectronic applications. Int Nano Lett 6:99-104

26. Kumaravel R, Menaka S, Snega SRM, Ramamurthi K, Jeganathan K (2010) Electrical, optical and structural properties of aluminum doped cadmium oxide thin films prepared by spray pyrolysis technique. Mater Chem Phys 122:444-448

27. Khan MAM, Khan W, Ahamed M, Alhoshan M (2012) Structural and optical properties of $\ln _{2} \mathrm{O}_{3}$ nanostructured thin film. Mater Lett 79:119-121

28. Khan MAM, Khan W (2016) Thickness-dependent structural and optoelectronic properties of $\ln _{2} \mathrm{O}_{3}$ films prepared by spray pyrolysis technique. J Electron Mater 45:4453-4459
29. Abdullah OG, Salman YAK, Saleem SA (2016) Electrical conductivity and dielectric characteristics of in situ prepared PVA/HgS nanocomposite films. J Mater Sci: Mater Electron 27:3591-3598

30. Bdewi SF, Abdullah OG, Aziz BK, Mutar AAR (2016) Synthesis, structural and optical characterization of $\mathrm{MgO}$ nanocrystalline embedded in PVA matrix. J Inorg Organomet Polym Mater 26:326-334

31. Kassim A, Nagalingam S, Min HS, Karrim N (2010) XRD and AFM studies of $\mathrm{ZnS}$ thin films produced by electrodeposition method. Arab J Chem 3:243-249

32. Abdullah OG, Aziz SB, Rasheed MA (2016) Structural and optical characterization of PVA: $\mathrm{KMnO}_{4}$ based solid polymer electrolyte. Results Phys 6:1103-1108

33. Abdullah OG, Saleem SA (2016) Effect of copper sulfide nanoparticles on the optical and electrical behavior of poly (vinyl alcohol) films. J Electron Mater 45:5910-5920

34. Anitha M, Tamilnayagam V, Anitha N, Amalraj L, Raj SG (2017) Investigations on the structural, electrical and optical properties of thin films of $\mathrm{CdO}_{(111)}$. J Mater Sci: Mater Electron 28:17297-17307

35. Shide SS, Shide PS, Pawar SM, Moholkar AV, Bhosale CH, Rajpure KY (2008) Physical properties of transparent and conducting sprayed fluorine doped zinc oxide thin films. Solid State Sci 10:1209-1214

36. Kumar PMR, Kartha CS, Vijayakumar KP (2005) Doping of spraypyrolyzed $\mathrm{ZnO}$ thin films through direct diffusion of indium: Structural optical and electrical studies. J Appl Phys 98:023509

37. Abdullah OG, Tahir DA, Kadir K (2015) Optical and structural investigation of synthesized PVA/PbS nanocomposites. J Mater Sci: Mater Electron 26:6939-6944

38. Abdullah OG, Aziz SB, Omer KM, Salih YM (2015) Reducing the optical band gap of polyvinyl alcohol (PVA) based nanocomposite. J Mater Sci: Mater Electron 26:5303-5309

39. Aziz SB, Abdullah OG, Hussein AM, Ahmed HM (2017) From insulating PMMA polymer to conjugated double bond behavior: green chemistry as a novel approach to fabricate small band gap polymers. Polymers 9:626

40. Abdullah OG (2016) Synthesis of single-phase zinc chromite nano-spinel embedded in polyvinyl alcohol films and its effects on energy band gap. J Mater Sci: Mater Electron 27:12106-12111

41. Russell SAO, Cao L, Qi D, Tallaire A, Crawford KG, Wee ATS, Moran DAJ (2013) Surface transfer doping of diamond by $\mathrm{MoO}_{3}$ : a combined spectroscopic and Hall measurement study. Appl Phys Lett 103:202112

42. Helen SJ, Devadason S, Haris M, Mahalingam T (2018) Transparent conducting Mo-doped CdO thin films by spray pyrolysis method for solar cell applications. J Electron Mater 47:2439-2446

43. Sankarasubramanian K, Sampath M, Archana J, Sethuraman K, Ramamurthi K, Hayakawa Y (2015) Influence of substrate temperature on ethanol sensing properties of $\mathrm{CdO}$ thin films prepared by facile spray pyrolysis method. J Mater Sci: Mater Electron 26:955-961

44. Yuasa M, Masaki T, Kida T, Shimanoe K, Yamazoe N (2009) Nanosized $\mathrm{PdO}$ loaded $\mathrm{SnO}_{2}$ nanoparticles by reverse micelle method for highly sensitive CO gas sensor. Sens Actuators, B 136:99-104

45. Ferro R, Rodriguez JA, Jimenez I, Cirera A, Cerda J, Morante JR (2005) Gas-sensing properties of sprayed films of $(\mathrm{CdO})_{x}(\mathrm{ZnO})_{1-x}$ mixed oxide. IEEE Sens J 5:48-52

46. Su PG, Peng SL (2015) Fabrication and NO2 gas-sensing properties of reduced graphene oxide/ $\mathrm{WO}_{3}$ nanocomposite films. Talanta 132:398-405 
47. Ramamoorthy R, Dutta PK, Akbar SA (2003) Oxygen sensors: materials, methods, designs and applications. J Mater Sci 38:4271-4282

48. Chen IC, Lin SS, Lin TJ, Hsu CL, Hsueh TJ, Shieh TY (2010) The assessment for sensitivity of a $\mathrm{NO}_{2}$ gas sensor with $\mathrm{ZnGa}_{2} \mathrm{O}_{4} /$ $\mathrm{ZnO}$ core-shell nanowires-a novel approach. Sensors 10:3057-3072
49. Pozos HG, Vidal JLG, Torres GA, Olvera ML, Castaneda L (2014) Physical characterization and effect of effective surface area on the sensing properties of tin dioxide thin solid films in a propane atmosphere. Sensors 14:403-415 